\title{
Mersin Silifke Mezgit Kale Anıt Mezarı Fotogrametrik Rölöve Alımı Ve Üç Boyutlu Modelleme Çalışması
}

\author{
Murat YAKAR ${ }^{1 *}$, Yusuf Doğan ${ }^{1}$ \\ ${ }^{1}$ Selçuk Üniversitesi, Mühendislik Fakültesi, Harita Mühendisliği Bölümü, Konya \\ (yakar@selcuk.edu.tr)
}

\begin{abstract}
$\ddot{\mathbf{O} z}$
Geçmişimiz ve geleceğimiz arasında köprü olan tarihi kültür varlıklarımızın yok olmaya yüz tuttuğu günümüzde kayıt altına alınarak korunması büyük bir ehemmiyet taşımaktadır. Bu eserlerin mevcut durumlarının tespit edilmesi, belgelenmesi, korunması ve gelecekte yapılabilecek yenileme çalışmalarında altlık olarak kullanılması açısından önemlidir.

$\mathrm{Bu}$ çalışma ile Mezgit Kale Anıt Mezarının fotogrametrik yöntemle ölçülmesi, üç boyutlu modellenmesi amaçlanmıştır. Çalışmada ölçümler, 5 adet poligon noktası yardımıyla yapıyı kapsayacak şekilde Kapalı Poligon Geçkisi tesis etmek suretiyle Topcon GPT - 3007 Reflektörsüz Total Station cihazı yardımıyla gerçekleştirilmiş olup poligon noktalarının koordinatları iki yarım silsile yöntemiyle lokal olarak hesaplanmıştır. Photomodeler programı ile arazide elde edilen veriler kullanılarak yapının gerçek ölçülerde üç boyutlu modeli oluşturulmuştur.
\end{abstract}

Anahtar Kelimeler: Fotogrametri, Mezgit Kale, Kültürel Miras, PhotoModeler, 3B Model

\section{Mersin Silifke Mezgit Kale Anıt Mezarı Fotogrametrik Rölöve Alımı Ve Üç Boyutlu Modelleme Çalışması}

\begin{abstract}
It is a great importance to record and protect the historical cultural assets that are bridging between our past and our future today. It is important that these works are used as a base for the identification, documentation, preservation and future work which can be done in the future.

With this study, it is aimed to measure Mesgit Castle Anit Mezarın by photogrammetric method and to model it in three dimensions. Measurements in the study were carried out with Topcon GPT - 3007 Reflectorless Total Station device by establishing Closed Polygon Pass to cover with 5 polygon points and the coordinates of polygon points were calculated locally by two half - way method. Using Photomodeler program and real data obtained from the field, three dimensional model was created in real scale
\end{abstract}

Keywords: Photogrammetry, Mezgit Castle, Cultural Heritage, Photomodeler, 3D Model

\section{GİRIŞ}

Tarihi kültür varlıkları üzerinde bulunduğu toprakların geçmişine 1 şık tutarken asırlar boyu ona sahip olan medeniyetin de zenginliğini ifade eder. $\mathrm{Ne}$ var ki bu zenginliklerin yok olmaması ve sonraki nesillere aktarılabilmesi için belgelemeye ve korumaya gereksinim duyulmaktadır. Tarihi anıtların ve alanların incelenmesine yönelik yöntemlerin geliştirilmesi, kültürel mirasın kayıt altına alınması ve algılanışı için gözlem yapılmasi; mimari, arkeolojik ve diğer sanat tarihi araştırması gibi alanlara yönelik herhangi bir değerli mimari veya diğer kültürel anıtın, nesnenin veya alanın korunması ve restorasyonu için önemli

* Sorumlu Yazar 
katkılar sağlar (Hanke ve Grussenmeyer, 2002). Sayisal yersel fotogrametri bir kamera ile yakın mesafeden çekilen sayısal görüntülerden ya da fotoğraflardan nesnelerin doğrudan ve kesin olarak ölçülmesi için kullanılan tekniktir. $\mathrm{Bu}$ yöntem arkeoloji, mimari, otomotiv ve uzay mühendisliği ve kaza yeri inceleme çalışmalarında başarılı bir şekilde uygulanmaktadır (Atkinson, 1996; Cooper and Robson, 1996; Slama, 1980). Sayısal yersel fotogrametri de kültürel mirasların belgelenmesinde etkili ve oldukça verimli bir yöntemdir.

Fotogrametri, yüksek kalitede fotorealistik model oluşturmak için iyi bir çözüm sağlar ve bu faydalar tarihi alanları korumak için sağl1klı belgeleme ihtiyacını karşılayabilir (Yakar vd, 2011). Tarihi ve kültürel mirasa konu objelerin istenilen ölçeklerde çizimleri, çerçeve ve üç boyutlu modelleri hızlı ve hassas bir şekilde yapilabilmektedir. Belgelenen üç boyutlu objelerin üzerlerine doku verileri de ilave edilerek üç boyutlu foto modelleri elde edilebilmektedir. (Yakar vd, 2009). Bu çalışmada sayısal yersel fotogrametri ile eserin foto modelinin oluşturulması amaçlanmıştır. Foto modelden, cisim üst yüzeyi fotografik doku ile kaplanmış üç boyutlu bir geometrik model (genellikle bir CAD-Vektör modeli) anlaşılmaktadır (Kraus, 2007).

\section{YÖNTEM}

\subsection{KORKUSUZ KRAL ANIT MEZARI (MEZGIT KALE)}

Susanoğlu'nun içinden kuzeye doğru giden yolun 10. Kilometresinde Paslı'ya ulaşı1ır. Paslı'da Roma dönemine ait çok sayıda ev, sarnıç ve mezar kalıntıları ile bir nekropol görülebilir. Paslı'nın $3 \mathrm{~km}$ doğusunda, bir küçük tepe üzerinde, Korkusuz Kral Anıtmezarı vardır. Yöre halkı tarafindan Mezgitkale olarak bilinen, İ.S. II. yy veya III. yy Roma dönemine ait bu anıtmezar oldukça iyi korunmuş durumdadır. Akdeniz'e bakan anıtmezar $7.80 \mathrm{~m}$ ebadında olup, ön kısmındaki Korint tarzında başlıklı sütunların ortasinda konsollar vardır. Bu konsollardan ortadaki ikisi üzerinde bulunan ayak oyuklarında zamanında mezarın heykeller taşıdığını anlıyoruz. Aynı konsol tipleri asıl mezar odasında da dört tane olarak görülür. Anitmezarın arka pedimentinde ortada bir kalkan; iki yanında kılıç ve akrep rölyefleri vardır. Mezaranıtın en önemli özelliği öndeki podyumun yan duvar taşı üzerine yontulmuş fallus kabartmasıdır. Fallus, döl ve dirim tanrısı Priapos mitini çağrıştırmaktadır. Anitmezar civarındaki 5x20x8 m ölçülerindeki kayadan kesme bir sarnıç ve zeytinyağı çıkarmada kullanılan dev taş silindirler görülebilecek diğer kalıntılardır (URL-1).

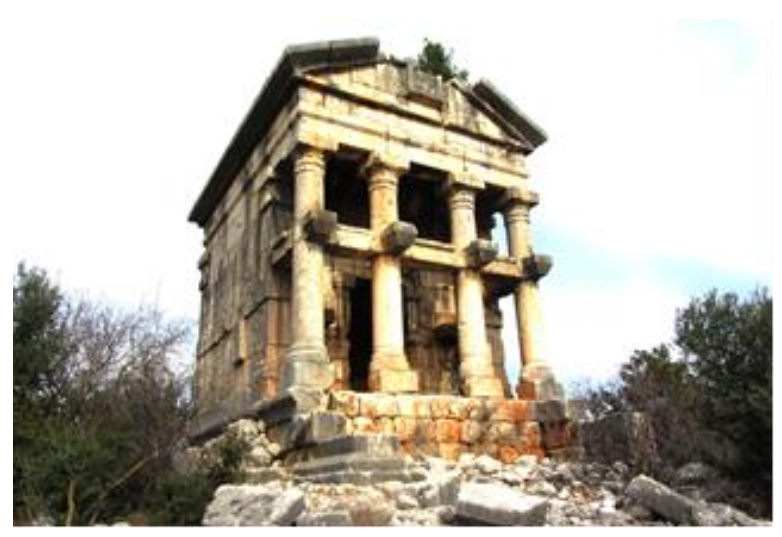

Şekil 1. Mezgitkale Anıt Mezarı (Ön Cephe)

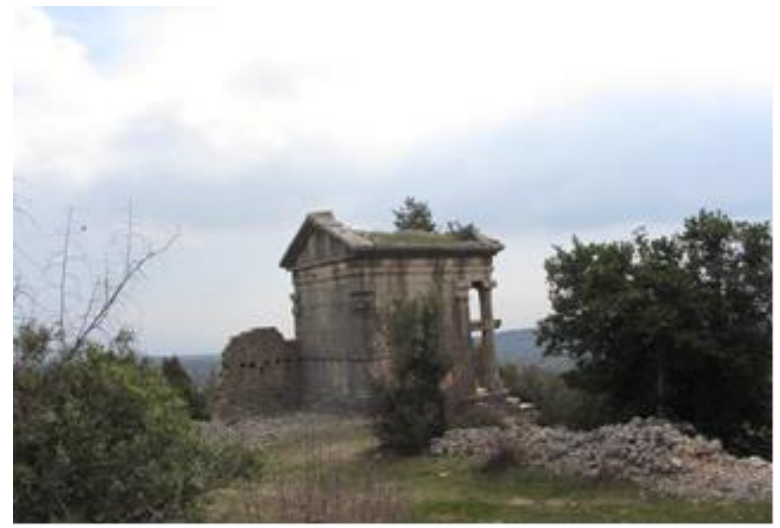

Şekil 2. Mezgitkale Anıt Mezarı (Arka Cephe)

Mezgitkale Anıt Mezarı Mersin ili Silifke ilçesi Öztürkmenli Mahallesinde 
bulunmaktadır. İlçe merkezine yaklaşık $30 \mathrm{~km}$ uzakta bulunmaktadır. Anit Mezara sahil yolu tarafinda Atakent Mahallesinden girilmekte olup buradan yaklaşı $13 \mathrm{~km}$ uzaktadır, ayrıca anıt mezara İmamlı ve Ovacık Mahalleleri üzerinden de geçilebilmektedir. Mezgitkaleye, Paslı mevkiinde doğuya sapılan yoldan yaklaşık $2 \mathrm{~km}$ gidildikten sonra ulaş1lır. Eserin coğrafi koordinatları $36^{\circ} 28^{\prime} 01.3^{\prime \prime} \mathrm{K}$ enlemi $34^{\circ} 01^{\prime} 37.3 " \mathrm{D}$ boylamında yer almaktadır. Yapı, inşa edildiği asır göz önüne alınırsa günümüzde genel itibariyle sağlam bir vaziyette durduğu görülmektedir. Yapının çatısında çökme olduğu ve toprakla dolu olduğu görülmüştür, ayrıca çatıda yetişmekte olan bir ağaca rastlanmıştır.

\subsection{Arazi Çalışması}

Arazide ölçüm işlemleri için reflektörsüz ölçüm yapabilen TOPCON GPT 3007 Total Station ve fotoğrafların çekilmesi için Canon PowerShot SX220 HS fotoğraf makinesi kullanılmıştır. Kroki olarak kullanılmak üzere eserin her cephesinin fotoğrafları çekildikten sonra çıktısı alınmıştır.

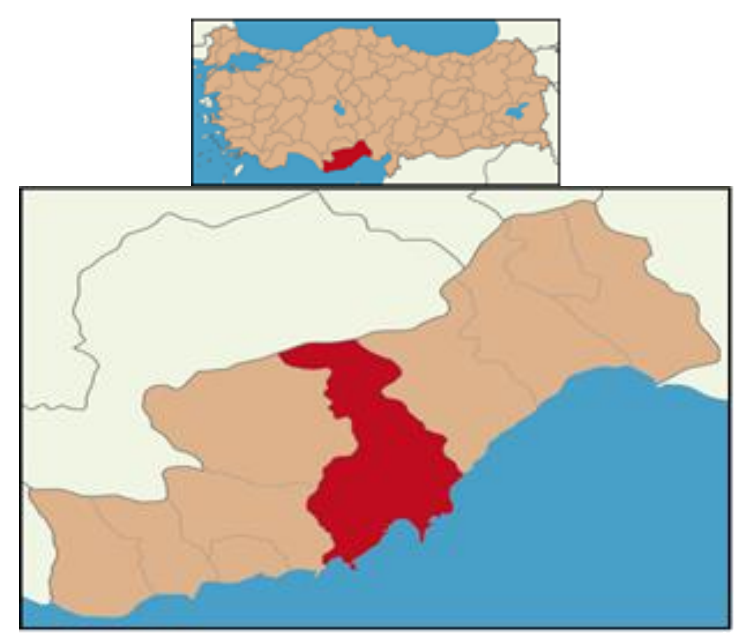

Şekil 3. Mersin ili ve Silifke ilçe Haritası (URL-2, URL-3)

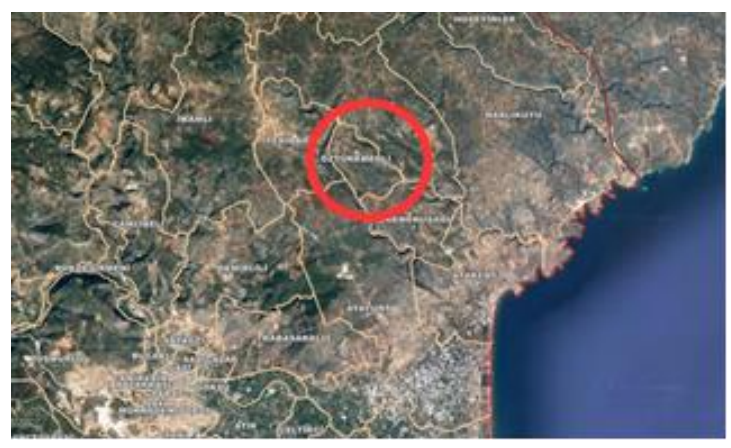

Şekil 4. Öztürkmenli Köyü (URL-4)

Anıt mezar etrafinda en az her üç nokta birbirini görecek şekilde poligon noktası tesis edilmiştir (Şekil 7). Kapalı poligon güzergah1 oluşturularak noktalar iki yarım silsile yöntemiyle lokal sistemde koordinatlandırılmıştır. Eserin daha önceden çekilen cephe fotoğraflarının çıktısı üzerinde de görülebilen detay noktalarından alım yapılarak çıktı üzerinde işaretlenmiştir. Eser üzerinden alınan bu koordinatlar üç boyutlu rölöve için kullanılan fotoğrafların dengelenmesinde kullanılmıştır. Fotoğraflar çekilirken eserin her yerini görecek şekilde farklı açılarda olmasına dikkat edilmiştir (Şekil 8). Arazi çalışması yarım gün gibi kısa bir zamanda gerçekleştirilmiştir.

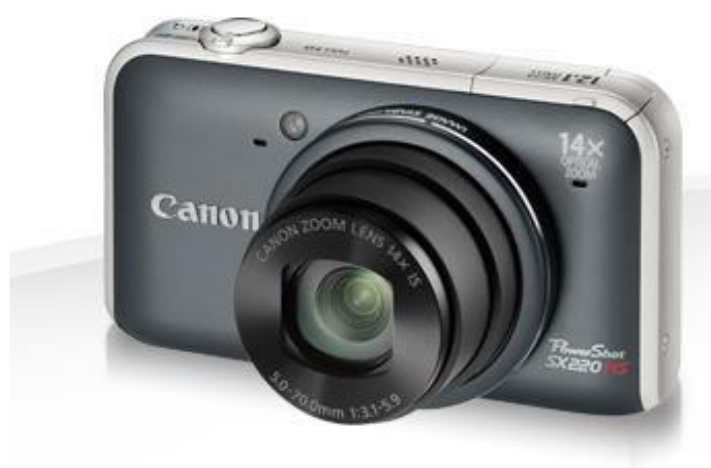

Şekil 5. Canon PowerShot SX220 HS (URL5) 


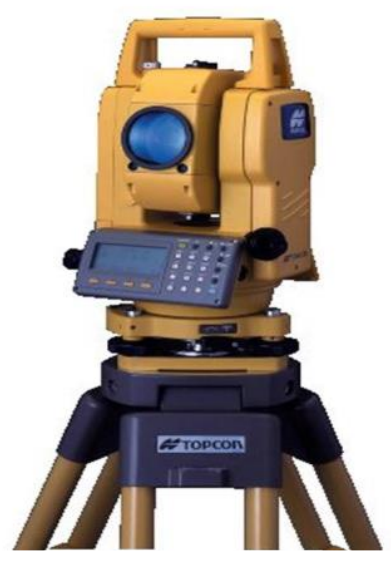

Şekil 6. TOPCON GPT 3007 Total Station (URL-6)

Eserin doğu kısmında bulunan ağaçlar fotoğraf çekiminde ve ölçümde sıkıntılara yol açmıştır. Şekil 7.'te görüleceği üzere P.2 noktasının diğer noktalara nispeten esere daha yakın olması bitki örtüsünden kaynaklanmaktadır. Ayrıca ofis çalışmasında işlem için yeterli olmayan bu cephenin görüntüleri tekrardan çekildi. Bina çatısının görüntüleri yükseklik sebebiyle toplanamadı; ancak İHA, merdiven gibi araçlar çatının fotoğraflarının çekilmesinde faydalı ve başarılı olabilir.

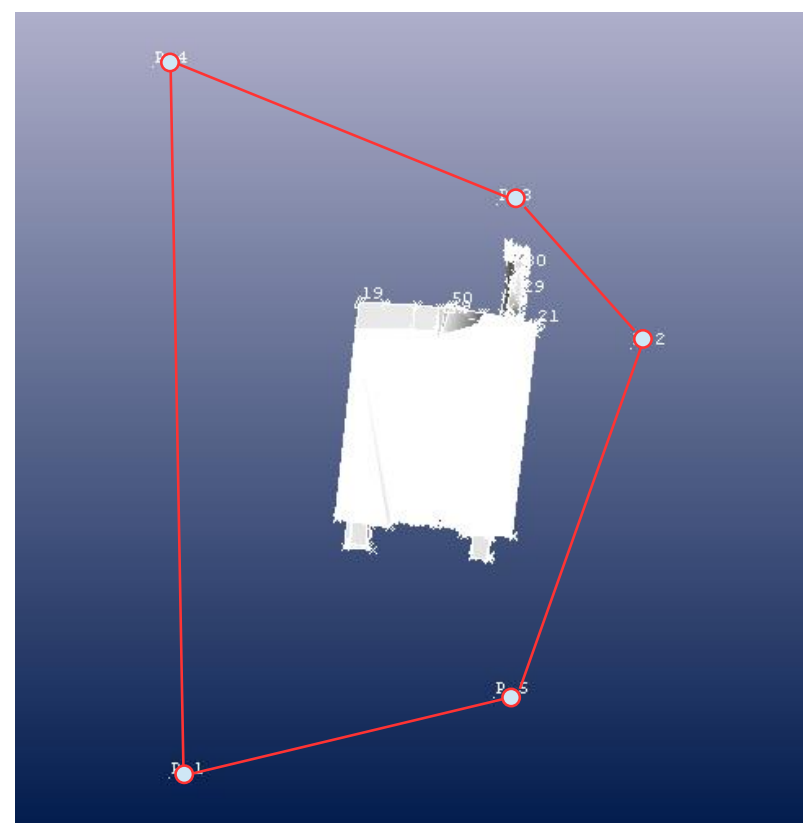

Şekil 7. Poligon Tesisi

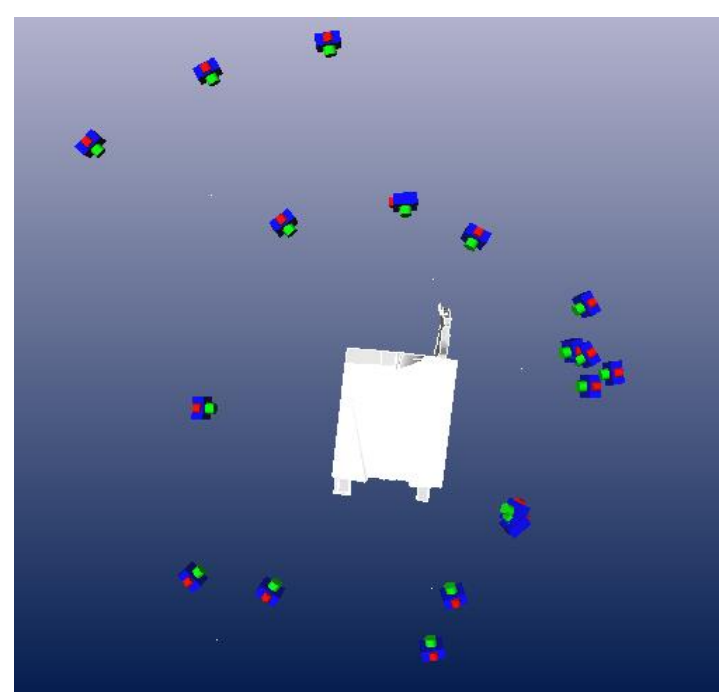

Şekil 8. Fotoğrafların Çekildiği Konumlar

Araziden elde edilen veriler PhotoModeler programına işlenmek üzere aktarılmıştır. Arazide kullanılan fotoğraf makinesinin PhotoModeler programı ile belirlenen kalibrasyon parametreleri projede kullanılmak üzere programa tanıtılmıştır. Eser üzerinden alınan detay noktalarının koordinatları fotoğrafların dengelenmesinde kullanılmıştır. Dengelenen fotoğraflar üzerinden eserin üç boyutlu çizim işlemleri gerçekleştirilmiştir. Büro çalışmaları bir hafta sürmüştür.

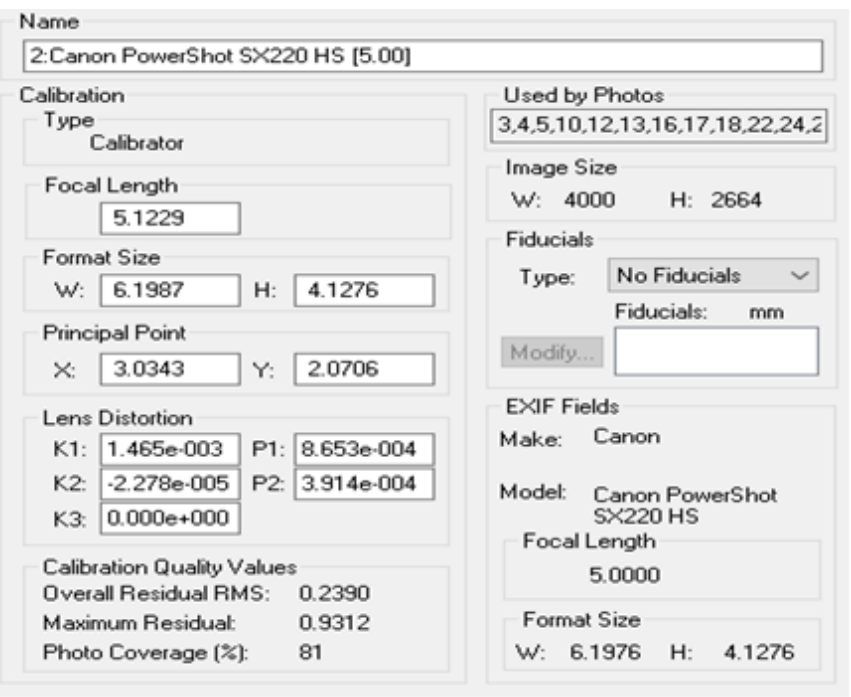

Şekil 9. Kalibrasyon Parametreleri 


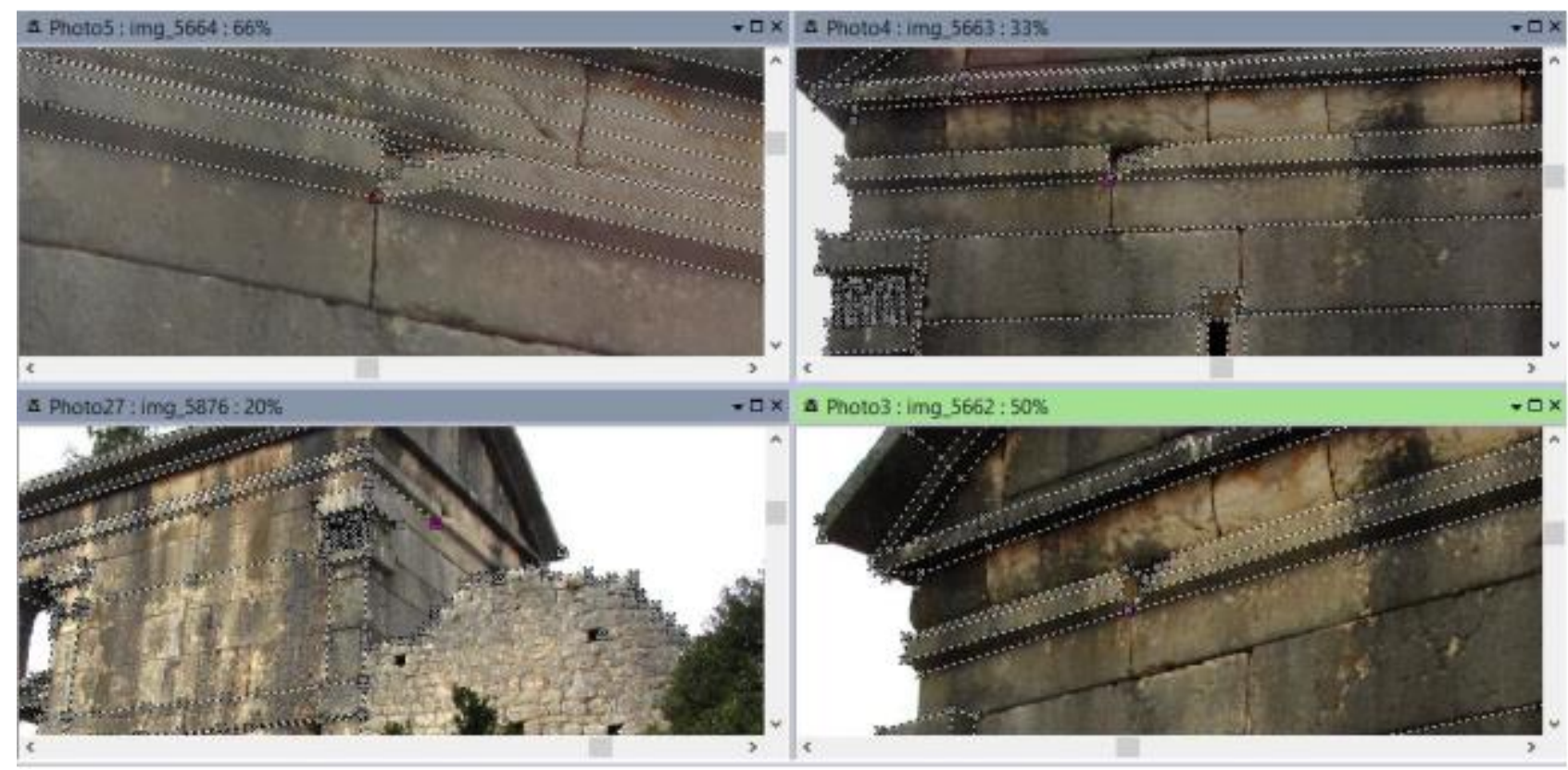

Şekil 10. Fotoğraflardan Detayların Çizimi

\section{SONUÇ}

Tarihi ve kültürel mirasların restore edilebilmesi ve korunabilmesi için sağl1klı bir şekilde belgelenmesi gerekmektedir. Belgeleme çalışmaları için kullanılan yöntemlerden biri ise fotogrametridir. $\mathrm{Bu}$ çalışmada sayısal yersel fotogrametri tekniği kullanılarak tarihi ve kültürel mirasların belgelenmesi amaçlanmıştır. $\mathrm{Bu}$ amaç doğrultusunda yapılan kısa süren arazi ve ofis çalışmasında fotogrametrik yöntemin zaman ve maliyet yönünden kazançlı ve avantajlı olduğu görülmüştür. Yöntemin bu denli avantajlı olması sayısal tarihi ve kültürel miras arşivinin olusturulmasında, yöntemi tercih edilebilir kılmaktadır. Bakımsızlık ve yok olma tehlikesiyle karşı karşıya kalan tarihi ve kültürel mirasların korunmasında fotogrametri yöntemi, belgeleme çalışmaları ve restorasyon işlemleri için yüksek doğruluklu çözümler sunmaktadır. Fotogrametri, fotoğraf ve matematiksel eşitlikleri kullanıdığından oluşturulan 3B model üzerinden doğru ve hassas ölçümler yapılabilmektedir. Mezgitkale Anıtmezarı gibi detaylı çizim isteyen yapılar ya da alanların çizimi fotogrametrik yöntemde bir kaç gün veya daha az bir sürede bitmekte ve üstelik veri kaybı olmadığından yüksek doğrulukla gerçekleştirilmektedir.

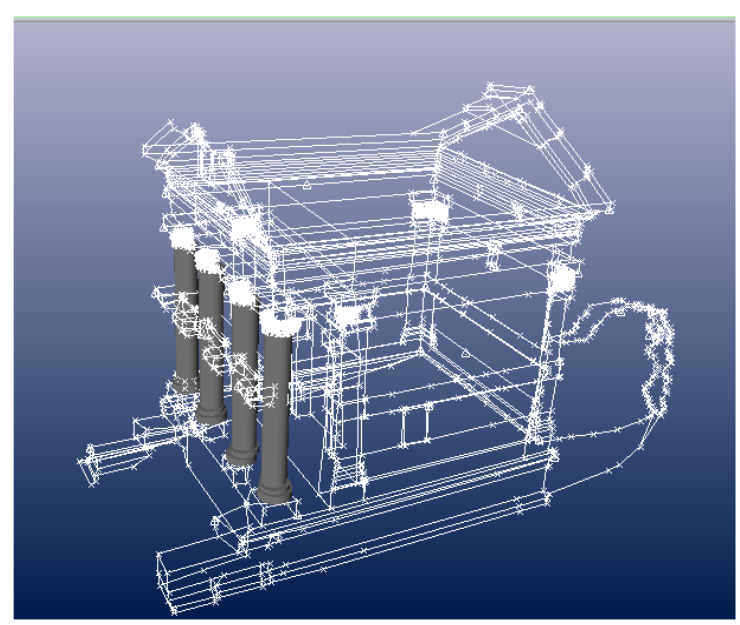

Şekil 7. Eserin 3B Modeli 


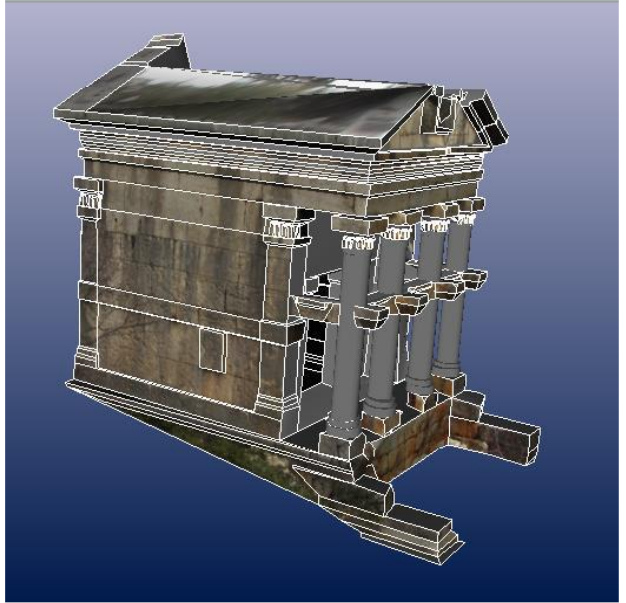

Şekil 11. PhotoModeler'da eserin çizilmiş hali

\section{KAYNAKÇA}

Yakar, M., Yılmaz, H.M., Yıldız, F., Zeybek, M., Şentürk, H., Çelik, H., (2009). SilifkeMersin Bölgesinde Roma Dönemi Eserlerinin 3-Boyutlu Modelleme Çalışması ve Animasyonu, TMMOB Harita ve Kadastro Mühendisleri Odası 12. Türkiye Harita Bilimsel ve Teknik Kurultayl, Ankara.

KRAUS, K., (2007). Fotogrametri, Fotoğraflardan ve Lazer Tarama Verilerinden Geometrik Bilgiler, Çeviri, ITÜ, Nobel Yayın Dağıtım, 405. (Çevirenler M.O.Altan vd.)

HANKE, K., GRUSSENMEYER, P., STREILEIN, A., (2002). Digital Photogrammetry, Taylor \& Francis, 300301. (Editörler M. KASSER and Y. EGELS)

YAKAR, M., YILDIZ, F., ZEYBEK, M., KOCAMAN, E., YOLCU, M., FILIZZ, T., (2011). Photogrammetric Modeling of Monuments Eflatunpınar, FIG Working Week 2011 Bridging the Gap between Cultures, Marrakech, Morocco.

ATKINSON, K,B., (1996). Close Range Photogrammetry and Machine Vision, Whittles Publishing, oseleigh House, Scotland, UK.
COOPER, M.A.R. and ROBSON, S., (1996). Theory of Close Range Photogrammetry, Close Range Photogrammetry and Machine Vision, Whittles Publishing, Roseleigh House, Latheronwheel, Caithness, Scotland, UK., ISBN: 9781870325-73(8), 9-50.

SLAMA, C.C., (1980). The Manual of Photogrammetry, 4th Edn., American Society of Photogrammetrists, Falls Church, VA., ISBN: 1-57083-071-1.

URL-1, 2017, http://www.mersinkulturturizm.gov.tr/TR, 73147/silifke.html

URL-2, 2017, https://commons.wikimedia.org/w/index.p hp?curid=7122745

URL-3, 2017, https://commons.wikimedia.org/w/index.p $\mathrm{hp}$ ? curid $=8088837$

URL-4, 2017, http://keos.silifke.bel.tr/keos/ URL-5, 2017, http://www.canon.com.tr

URL-6, 2017, http://www.wsource.me/totalstation-topcon.html 